Article

\title{
Fluorinated Polyethylene Propylene Ferroelectrets with an Air-Filled Concentric Tunnel Structure: Preparation, Characterization, and Application in Energy Harvesting
}

\author{
Xi Zuo ${ }^{1,2} \oplus$, Li Chen ${ }^{1}$, Wenjun Pan ${ }^{1}$, Xingchen Ma ${ }^{1}$, Tongqing Yang ${ }^{2, *}$ and Xiaoqing Zhang ${ }^{1, *}$ \\ 1 Shanghai Key Laboratory of Special Artificial Microstructure Materials and Technology, School of Physics \\ Science and Engineering, Tongji University, Shanghai 200092, China; 1832882@tongji.edu.cn (X.Z.); \\ 18916269332@163.com (L.C.); wjpan_tj@163.com (W.P.); maxingchen@tongji.edu.cn (X.M.) \\ 2 School of Materials Science and Engineering, Tongji University, Shanghai 200092, China \\ * Correspondence: yangtongqing@tongji.edu.cn (T.Y.); x.zhang@tongji.edu.cn (X.Z.)
}

Received: 2 November 2020; Accepted: 29 November 2020; Published: 1 December 2020

\begin{abstract}
Fluorinated polyethylene propylene (FEP) bipolar ferroelectret films with a specifically designed concentric tunnel structure were prepared by means of rigid-template based thermoplastic molding and contact polarization. The properties of the fabricated films, including the piezoelectric response, mechanical property, and thermal stability, were characterized, and two kinds of energy harvesters based on such ferroelectret films, working in 33- and 31-modes respectively, were investigated. The results show that the FEP films exhibit significant longitudinal and radial piezoelectric activities, as well as superior thermal stability. A quasi-static piezoelectric $d_{33}$ coefficient of up to $5300 \mathrm{pC} / \mathrm{N}$ was achieved for the FEP films, and a radial piezoelectric sensitivity of 40,000 pC/N was obtained in a circular film sample with a diameter of $30 \mathrm{~mm}$. Such films were thermally stable at $120{ }^{\circ} \mathrm{C}$ after a reduction of $35 \%$. Two types of vibrational energy harvesters working in 33-mode and 31-mode were subsequently designed. The results show that a power output of up to $1 \mathrm{~mW}$ was achieved in an energy harvester working in 33-mode at a resonance frequency of $210 \mathrm{~Hz}$, referring to a seismic mass of $33.4 \mathrm{~g}$ and an acceleration of $1 \mathrm{~g}$ ( $\mathrm{g}$ is the gravity of the earth). For a device working in 31-mode, a power output of $15 \mu \mathrm{W}$ was obtained at a relatively low resonance frequency of $26 \mathrm{~Hz}$ and a light seismic mass of $1.9 \mathrm{~g}$. Therefore, such concentric tunnel FEP ferroelectric films provide flexible options for designing vibrational energy harvesters working either in 33-mode or 31-mode to adapt to application environments.
\end{abstract}

Keywords: ferroelectrets; longitudinal piezoelectric effect; radial piezoelectric effect; energy harvester; concentric tunnel structure; fluorinated polyethylene propylene

\section{Introduction}

Recent decades have witnessed the increasing development of energy harvesting technology, which is driven by the demand for self-powered portable devices and wireless sensor network nodes in the Internet of Things (IoT) [1-9]. Energy harvesting refers to a renewable distributed energy technique converting ignored energy sources in environments, such as solar energy, heat gradient energy, and mechanical energy, into useful electrical energy. Among these energy sources, mechanical energy is available almost everywhere and can be harvested by means of electromagnetic, electrostatic, triboelectric, or piezoelectric transduction [10]. For the harvesters utilizing piezoelectric mechanisms, named piezoelectric harvesters (PEHs), one of the critical elements in the devices is the piezoelectric transducer, whose performance is strongly dependent on the properties of the piezoelectric 
materials [11]. Because of their small size, thin-film structure, high energy conversion efficiency, and durability, intensive studies have been conducted on PEHs as microelectromechanical system (MEMS) generators [12].

A variety of piezoelectric materials, including piezoelectric ceramics [13,14], ferroelectric polymers [15], and ferroelectrets [16], have been adopted in energy harvesting. Among them, the ferroelectret is a relatively new one that was first used in energy harvesters in 2012 [17]. However, owing to its specific features, such as strong piezoelectric effect, flexibility, environmental-friendliness, small acoustic impedance, easy processing, and low cost, more and more attention has been paid to ferroelectret-based energy harvesters in recent years [18].

Many kinds of polymers have been used to prepare ferroelectret films, including polypropylene (PP) [19], irradiation-crosslinked polypropylene (IXPP) [20], polytetrafluoroethylene (PTFE) [21], fluorinated polyethylene propylene (FEP) [22], cycloolefin copolymer (COC) [23], polyethylene-naphthalate (PEN) [24], cyclic transparent optical polymer (CYTOP) [25], polylactic acid (PLA) [26], etc. Considering energy harvesters are likely to work in harsh environments with high humidity and elevated temperatures, hydrophobic and thermally stable ferroelectrets are more favorable. Normally the hydrophobicity requirement can be met by packaging devices with waterproof plastics [27]. Therefore, it is apparent that thermal stability is a more critical issue in ferroelectrets. Relevant articles describe a significant improvement in thermal stability of FEP laminated samples compared to PP samples whose working temperature is normally less than $50^{\circ} \mathrm{C}$. These samples exhibit stable piezoelectric properties at $90^{\circ} \mathrm{C}$ or higher [22,28].

In our prior work, we prepared laminated FEP ferroelectret films with an air-filled parallel tunnel structure exhibiting strong longitudinal and transverse piezoelectric effects. Furthermore, the vibrational energy harvesters based on such material can generate high power when working in 31-mode [22,29,30]. Being an extension of this concept, FEP ferroelectret films with a concentric tunnel structure were designed and prepared in this study. The fabricated films display similar properties as parallel tunnel samples with remarkable longitudinal and radial piezoelectric activities $[29,31]$. However, differing from parallel tunnel FEP ferroelectret films, the presently studied samples can be subjected to stresses on a two-dimensional plane as when working in 31-mode, which may increase flexibility in device design. Because of their radially symmetrical structure, concentric tunnel FEP ferroelectret films could be a more promising option for piezoelectric circular diaphragm (PCD) harvesters, which feature greater response to small strains and higher output power than cantilever beam harvesters. In this article, we report the preparation and characterization of concentric tunnel FEP ferroelectret films, and explore their applications in vibrational energy harvesters working in 33- and 31-modes.

\section{Preparation and Characterization of Concentric Tunnel FEP Films}

\subsection{Preparation Procedure}

The $12.5 \mu \mathrm{m}$ thick FEP films used in this study were supplied by DuPont. The preparation procedure of concentric tunnel films is schematically shown in Figure 1. Firstly, a pair of rigid circular templates with multiple homocentric annular 'ditches' were made. The ditches had a width of $1.5 \mathrm{~mm}$ and a depth of $0.5 \mathrm{~mm}$. The distance between the adjacent ditches was $0.5 \mathrm{~mm}$. In the preparation process, two FEP films and a soft rubber pad were first sandwiched between two templates in sequence as shown in Figure 1A. The soft rubber pad served as a buffer during the patterning step. Then, the films were patterned at a temperature of $40{ }^{\circ} \mathrm{C}$ and a pressure of $2 \mathrm{MPa}$ for $4 \mathrm{~min}$ (Figure 1B). These parameters are used for obtaining a plastic deformation in FEP films at a relatively low temperature with the help of pressure. After that, the soft pad was removed, two layers of films were buckled together with the templates (Figure 1C), and the stacks were heated in a muffle furnace for $13 \mathrm{~min}$ at $320^{\circ} \mathrm{C}$. [22] After cooling at room temperature, fusion bonding of the two patterned FEP films was achieved, thus obtaining a film with an air-filled concentric tunnel structure (Figure 1D,E). 
Figure $1 \mathrm{~F}$ and $1 \mathrm{G}$ show an optical image and cross-sectional scanning electron microscope (SEM) image of the fabricated concentric tunnel FEP films, respectively.

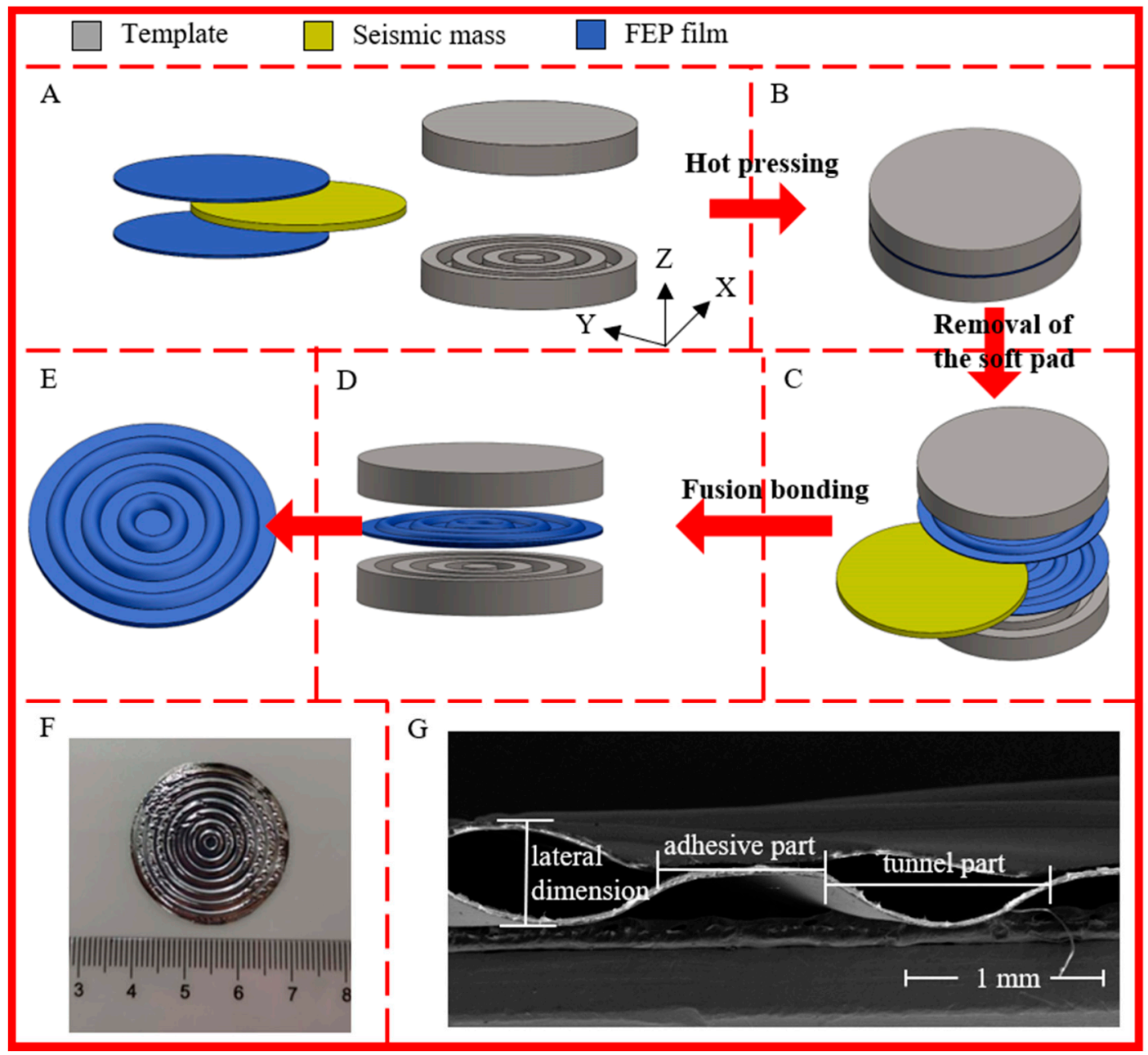

Figure 1. Schematic of fabrication and images of the concentric tunnel fluorinated polyethylene propylene (FEP) films. (A) Stacking sequence. (B-D) are the steps of thermoplastic molding. (E-G) are the schematic model, optical image, and cross-sectional SEM image of concentric tunnel FEP films, respectively.

As shown in Figure 1G, owing to the special tunnel structure, the samples were divided into the bonded parts and the air-filled tunnel parts, whose thickness was obviously uneven. The minimum thickness, $t_{\mathrm{min}}$, which referred to the bonded parts of the two layers of FEP films, was assumed to be $25 \mu \mathrm{m}$. At the same time, with a pressure of $0.36 \mathrm{kPa}$ applied on the entire upper surface by the F-55 thickness gauge, the maximum thickness, $t_{\max }$ corresponding to the center of the tunnel area was measured as approximately $340 \mu \mathrm{m}$ for the samples.

In the following charging step, the concentric tunnel FEP films were first metallized with $\mathrm{Al}$ on both surfaces. Then, the internal charging of the tunnels was achieved by contact charging in air with triangular voltages as shown in Figure 2A. The triangular voltages were provided by a ferroelectric analyzer (Radiant Precision Multiferroic II), and their periods in the present case were $5 \mathrm{~ms}$, as seen in Figure 2B. Figure 2C shows hysteresis loops of an FEP sample polarized by various peak voltages. The voltages were applied for many cycles, and always terminated electronically at zero to achieve the maximum polarization. Previous work indicated that the permanent charge density, which is corresponds to the induced charge density on the external electrode, is a function of the applied 
peak voltage [32]. As shown in Figure 2D, the charge density reached about $0.55 \mathrm{mC} / \mathrm{m}^{2}$ at a peak voltage of $2 \mathrm{kV}$.
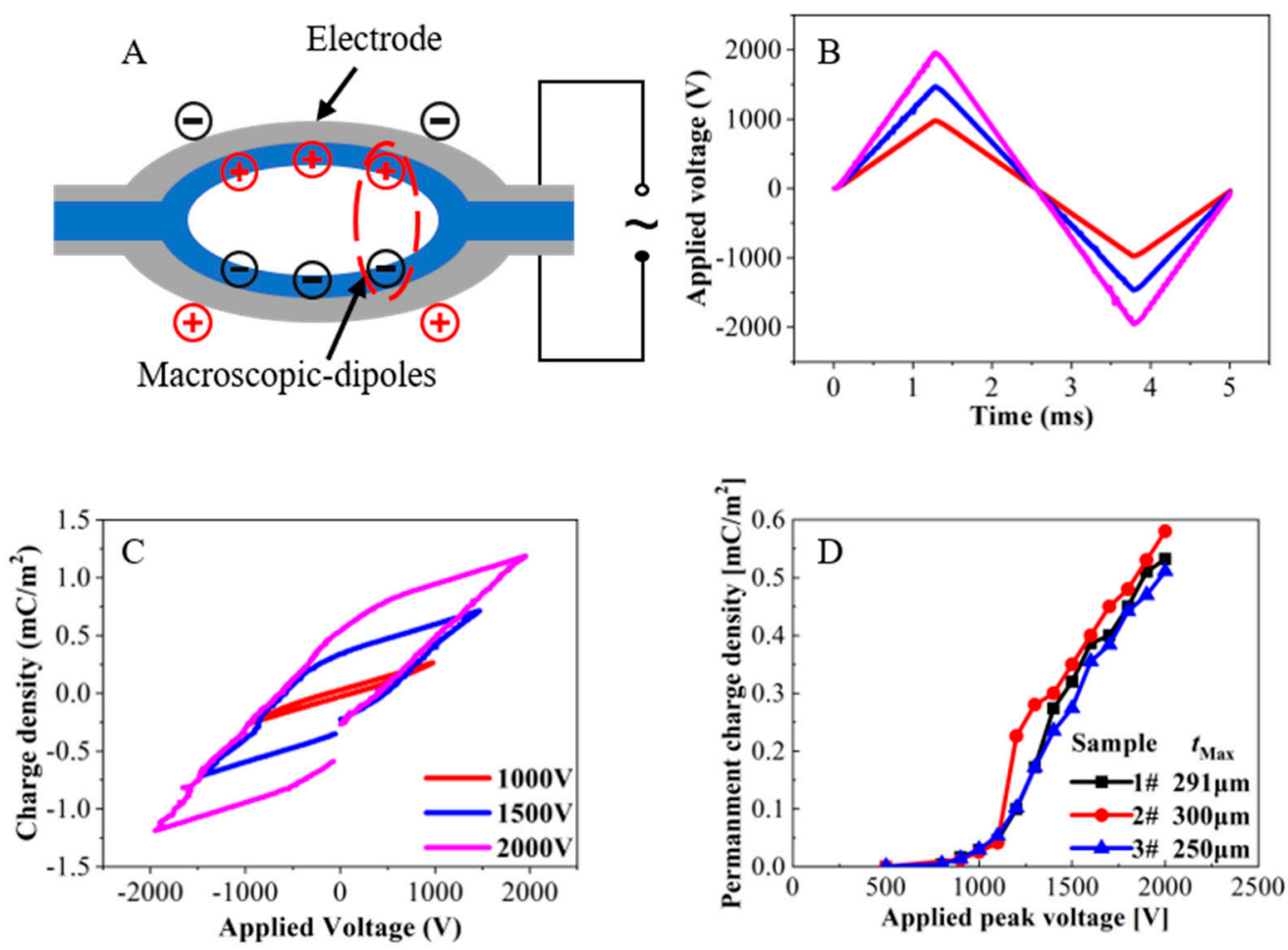

Figure 2. Contact polarization of the concentric tunnel FEP films. (A) Schematic of contact polarization. (B) Triangular voltage applied to the films. (C) Hysteresis loops of an FEP sample polarized by different applied peak voltages. (D) Permanent charge density on the external electrode as a function of the applied peak voltage.

\subsection{Piezoelectric Response}

The piezoelectric coefficient is an important parameter reflecting the coupling effect between mechanical and electric quantities of piezoelectric materials. In the present work, three methods, namely quasi-static, dynamic, and acoustic methods, were utilized to characterize the piezoelectric properties in the concentric tunnel FEP films. The longitudinal piezoelectric coefficient $d_{33}$ can be directly determined by the following equation [33]:

$$
d_{33}=Q / F
$$

where $Q$ and $F$ are the induced charges on the surface electrodes and the force applied to the sample, respectively. Although it is complicated to directly measure the radial piezoelectric coefficient, $d_{31}$, of the sample with such a complex structure, we propose a radial sensitivity, $M_{r}$, being relative to the location of the force applied, representing the piezoelectric effect in the radial direction of the ferroelectret samples. In this study, the force is applied to the centermost area of the sample. Thus, the $M_{r}$ can also be derived from

$$
M_{r}=Q / F
$$

\subsubsection{Measurement of Piezoelectric Responses by Quasi-Static Method}

Using the quasi-static method, as a certain external mechanical force, $F$, was applied to or removed from the sample in the z-direction, the induced charge $Q$ generated on the surface electrodes was recorded by an electrometer (Keithley 6514), thereby directly calculating $d_{33}$ and $M_{r}$ following Equations 
(1) and (2). The quasi-static method was also used to reflect the pressure dependence of the piezoelectric activity in the concentric tunnel FEP films.

In order to measure the quasi-static coefficient $d_{33}$, the sample was sandwiched between the working stage and a circular metal plate (see Figure 3A). The plate had the same diameter as the sample $(30 \mathrm{~mm})$ and served as a static pre-load to ensure that the tunnels were slightly deformed to avoid a bending effect. The force was provided by a series of weights ranging from 10 to $200 \mathrm{~g}$. Since in practice, removal of weights was much more easily controlled than their application, the weights were placed on the plate for a relatively long time and then rapidly removed. The induced charge, $Q$, integrated over $10 \mathrm{~s}$ after weight removal was recorded by an electrometer.

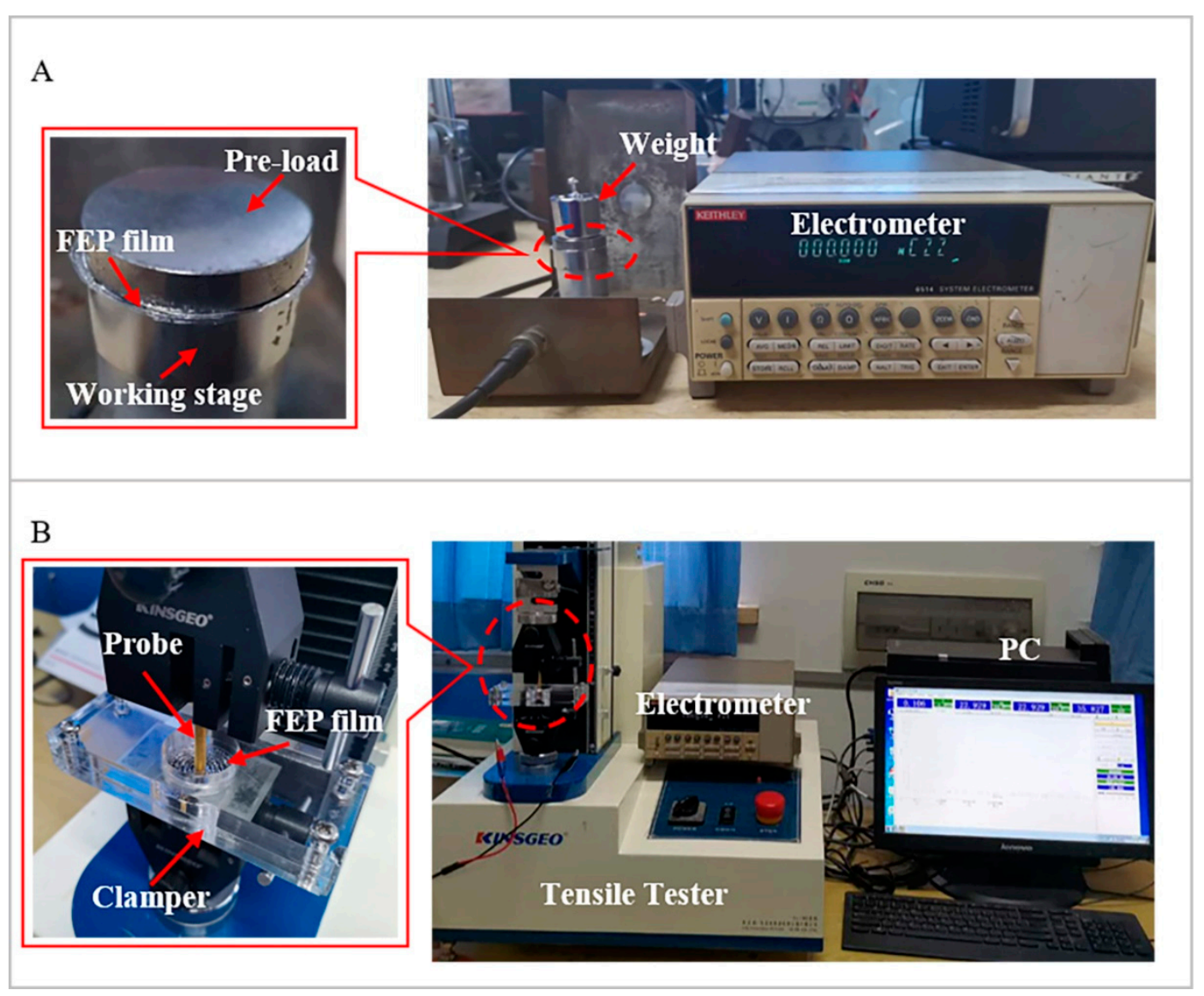

Figure 3. (A) Setup for measurement of the quasi-static coefficient, $d_{33}$, in concentric tunnel FEP films.

(B) Setup for measurement of quasi-static radial piezoelectric sensitivity, $M_{r}$.

Figure 3B shows the measuring setup for the quasi-static radial piezoelectric sensitivity, $M_{r}$. In this case, the edge of the sample was clamped, while the center part was free. The sample was stretched radially with a static force, $F$, applied at its center by a tensile tester (KJ-1065A) equipped with a cylindrical probe. The diameter of the probe was $2 \mathrm{~mm}$, which was the same size as that of the centermost circular bonded part. When the static force was applied to the sample, all tunnels were stretched in the radial direction. The induced charge was recorded by the electrometer after the removal of the force.

\subsubsection{Pressure Dependence}

As mentioned above, the quasi-static longitudinal and radial piezoelectric responses were measured to investigate the pressure dependence of the concentric tunnel FEP films. Results on the relation between the quasi-static piezoelectric coefficient $d_{33}$ and the applied pressure for three FEP film samples are illustrated in Figure 4A. This figure indicates the example of sample 3, marked in blue, 
in a small pressure range from 100 to $1960 \mathrm{mN}$. The $d_{33}$ coefficients increased steadily from $4261 \mathrm{pC} / \mathrm{N}$ at $100 \mathrm{mN}$ to $5233 \mathrm{pC} / \mathrm{N}$ at $490 \mathrm{mN}$. As the force continued to increase, the values started to level off and then remained at $5280 \mathrm{pC} / \mathrm{N}$ within a higher-pressure range of $490 \mathrm{mN}$ to $1960 \mathrm{mN}$. The results indicate that the samples had higher longitudinal piezoelectric activity at a relatively low pressure of about $490 \mathrm{mN}$.
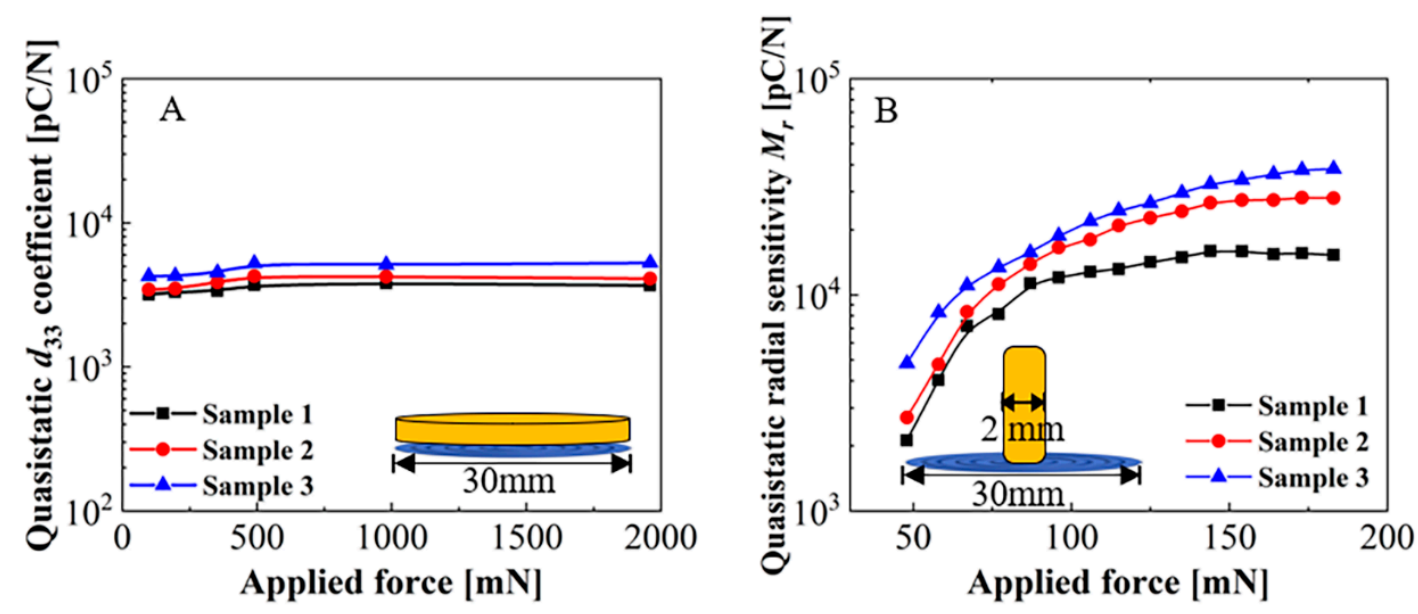

Figure 4. Pressure dependence of the concentric tunnel FEP films with diameters of $30 \mathrm{~mm}$. (A) Quasi-static piezoelectric coefficients, $d_{33}$, as a function of applied force. (B) Quasi-static radial sensitivity, $M_{r}$, as a function of applied force on the centermost area for FEP samples.

The results of the quasi-static radial piezoelectric sensitivity, $M_{r}$, indirectly reveal the pressure dependence of the radial piezoelectric activity. As shown in Figure $4 \mathrm{~B}$, three typical samples were tested under the same conditions. Taking sample 3 as an example, one observes that the $M_{r}$ increases sharply from $4820 \mathrm{pC} / \mathrm{N}$ to $18,767 \mathrm{pC} / \mathrm{N}$ at relatively small static forces ranging from 50 to $100 \mathrm{mN}$, while the rate of increase then slows down with the force increasing from 100 to $200 \mathrm{mN}$. The values reach up to around 40,000 pC/N at $200 \mathrm{mN}$. Despite the inconsistent behaviors of the samples, which is due to inevitable structural differences during the preparation process under the given experimental conditions in our lab, the results have import for determining the order of magnitude. The large radially piezoelectric sensitivity must be attributed to the significant amplification of applied force in 31-mode [22]. More work is underway to improve the uniformity of the samples.

\subsubsection{Measurement of Piezoelectric Responses by Dynamic Method}

The subsequent dynamic measurements showed the frequency dependence of the concentric tunnel FEP films and helped to assess their potential applicability at different frequencies. The vibration system for dynamic measurement consisted of a digital audio analyzer (dScope Series III), a vibration exciter (B\&K, Type 4809), a power amplifier (B\&K, Type 2713), a charge amplifier (B\&K, Type 2635), and an accelerometer (B\&K 4382). The acceleration of the system was provided by the exciter, which was driven by the signal generated by the digital audio analyzer by virtue of the power amplifier. The charge generated on the electrode in short circuit was amplified by the charge amplifier, collected by the digital audio analyzer, and recorded by a computer, and the applied acceleration, $a$, was measured by the accelerometer.

The dynamic $d_{33}$ coefficient was measured with the setup shown in Figure $5 \mathrm{~A}$. The loaded forces on the sample were composed of a static force of $m g$ and a dynamic force of $m a$ [34]. A pre-load with a diameter of $30 \mathrm{~mm}$ and a mass of $30 \mathrm{~g}$ was placed directly at the top of the sample without adhesion. Thus, during vibration, the acceleration had to be limited to $2.7 \mathrm{~m} / \mathrm{s}^{2}$ or less to avoid the sliding of the seismic mass. Meanwhile, the experimental setup for dynamic sensitivity, $M_{r}$, is depicted in Figure 5B. The seismic mass placed at the center part had a diameter of $8 \mathrm{~mm}$ and a weight of $1.2 \mathrm{~g}$. 

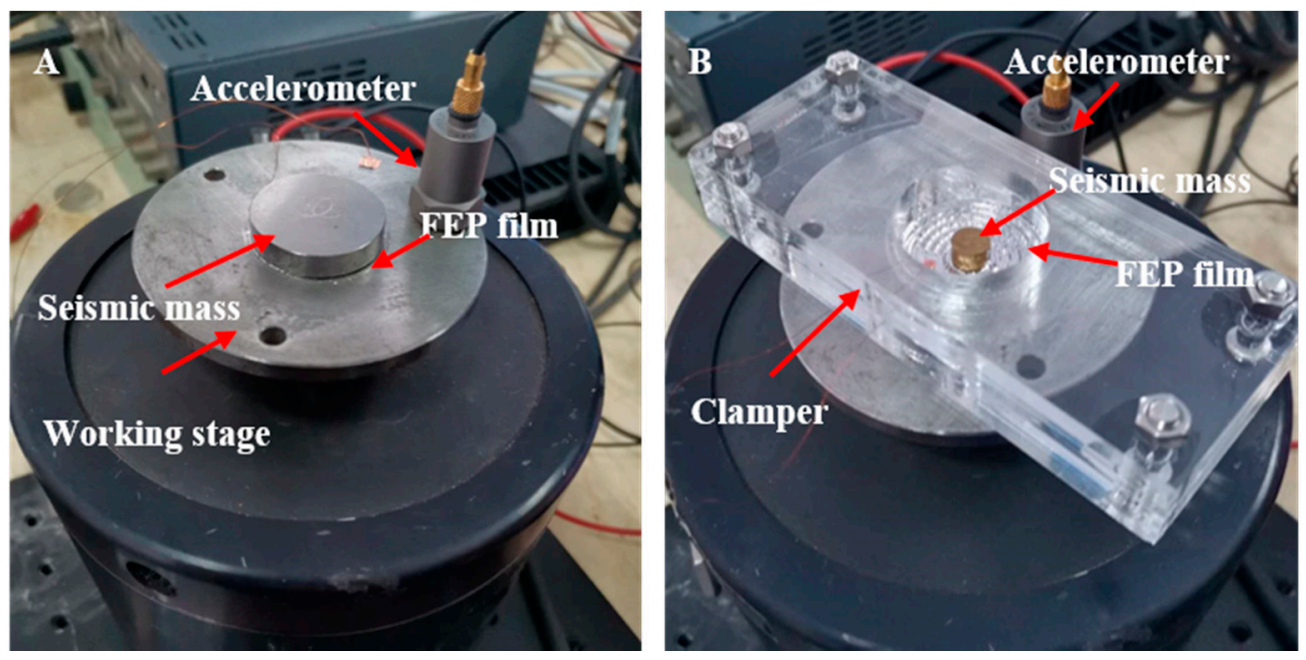

Figure 5. (A) Setup for measurement of the dynamic coefficient, $d_{33}$, of the concentric tunnel FEP films. (B) Setup for measurement of the dynamic radial piezoelectric sensitivity, $M_{r}$.

\subsubsection{Frequency Dependence}

Results on the dynamic piezoelectric responses are illustrated in Figure 6. The results not only indicate the frequency dependence of the longitudinal and radial piezoelectric responses, but also the information of the resonance frequency of 33-mode and 31-mode energy harvesters.
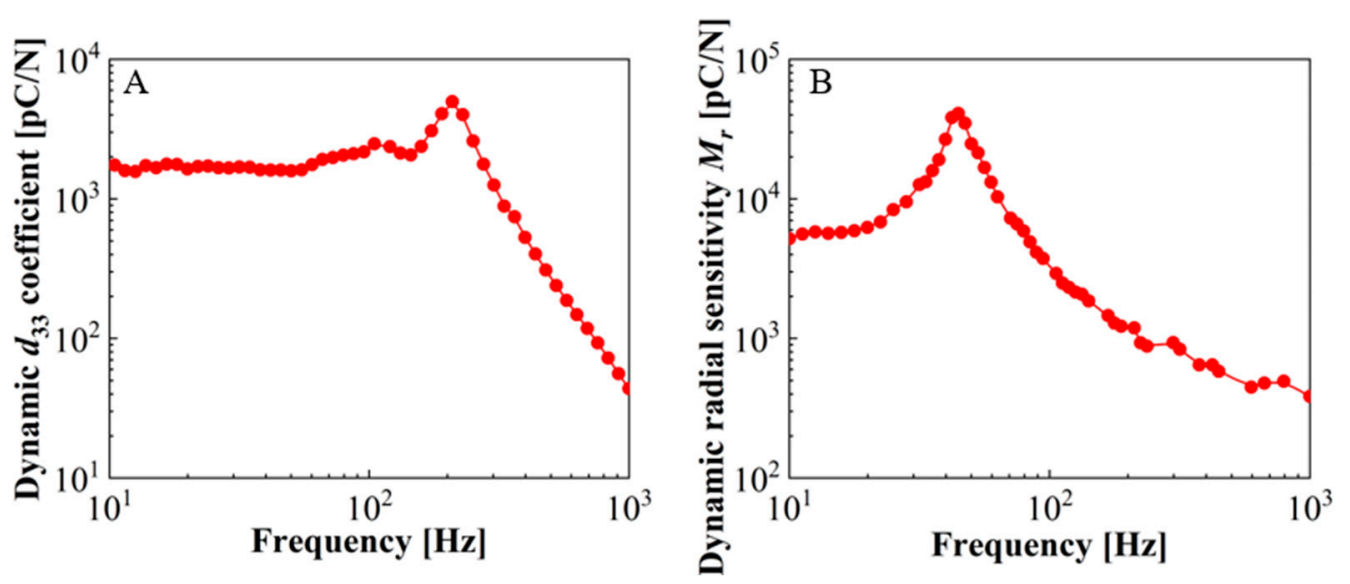

Figure 6. Frequency dependence of the concentric tunnel FEP films. (A) Dynamic piezoelectric coefficient, $d_{33}$, as a function of frequency. (B) Dynamic piezoelectric radial sensitivity, $M_{r}$, as a function of frequency.

The resulting frequency dependence of the $d_{33}$ coefficient for a representative sample with a quasi-static $d_{33}$ coefficient of $4346 \mathrm{pC} / \mathrm{N}$ is shown in Figure 6A. The experimental frequency ranged from 10 to $1000 \mathrm{~Hz}$, and the seismic mass was $30 \mathrm{~g}$. As the frequency of the vibration system increased, the dynamic $d_{33}$ was stabilized over a low-frequency range of 10 to $150 \mathrm{~Hz}$ around $1700 \mathrm{pC} / \mathrm{N}$. The piezoelectric response then reached a peak of $4979 \mathrm{pC} / \mathrm{N}$ at the resonance around $210 \mathrm{~Hz}$, followed by a dramatic drop as expected. The dynamic radial sensitivity $M_{r}$ of the same sample with a seismic mass of $1.2 \mathrm{~g}$ is depicted in Figure $6 \mathrm{~B}$. The dynamic $M_{r}$ is calculated as $40,900 \mathrm{pC} / \mathrm{N}$ at the resonance frequency of about $45 \mathrm{~Hz}$. The radial piezoelectric activity of the sample also remained at a high level at resonance, but decreased significantly with the increase of the frequency above resonance. 


\subsubsection{Measurement of $\mathrm{d}_{33}$ by Acoustic Method}

In this work, the acoustic method was also carried out to determine the dynamic coefficient $d_{33}$ (see Figure 7) [32]. The advantage of this method is that although the surface is uneven, the dynamic coefficient $d_{33}$ can be determined as an average value by applying a free-field sound pressure, $p$, on the sample. The $30 \mathrm{~mm}$ diameter test microphone consisted of the sample and an Al housing, which was utilized to ensure good shielding for acoustic measurements. The sound source was provided by a computer-controlled dynamic loudspeaker with a 300-1000 Hz broadband response and was amplified simultaneously by a power amplifier (DSPPA MP200PIII). The induced charge, $Q$, was amplified with a charge amplifier (AFT-0966) and then recorded by a signal collector (MI, VT DSO-2820). In this case, the loudspeaker, the test microphone together with a calibrated quarter-inch microphone (KW-4420), which was used to determine the reference free-field sound pressure $p$, were all located in an anechoic chamber. The test microphone and the calibrated microphone were placed equidistantly on both sides along the center axis $30 \mathrm{~cm}$ from the loudspeaker.

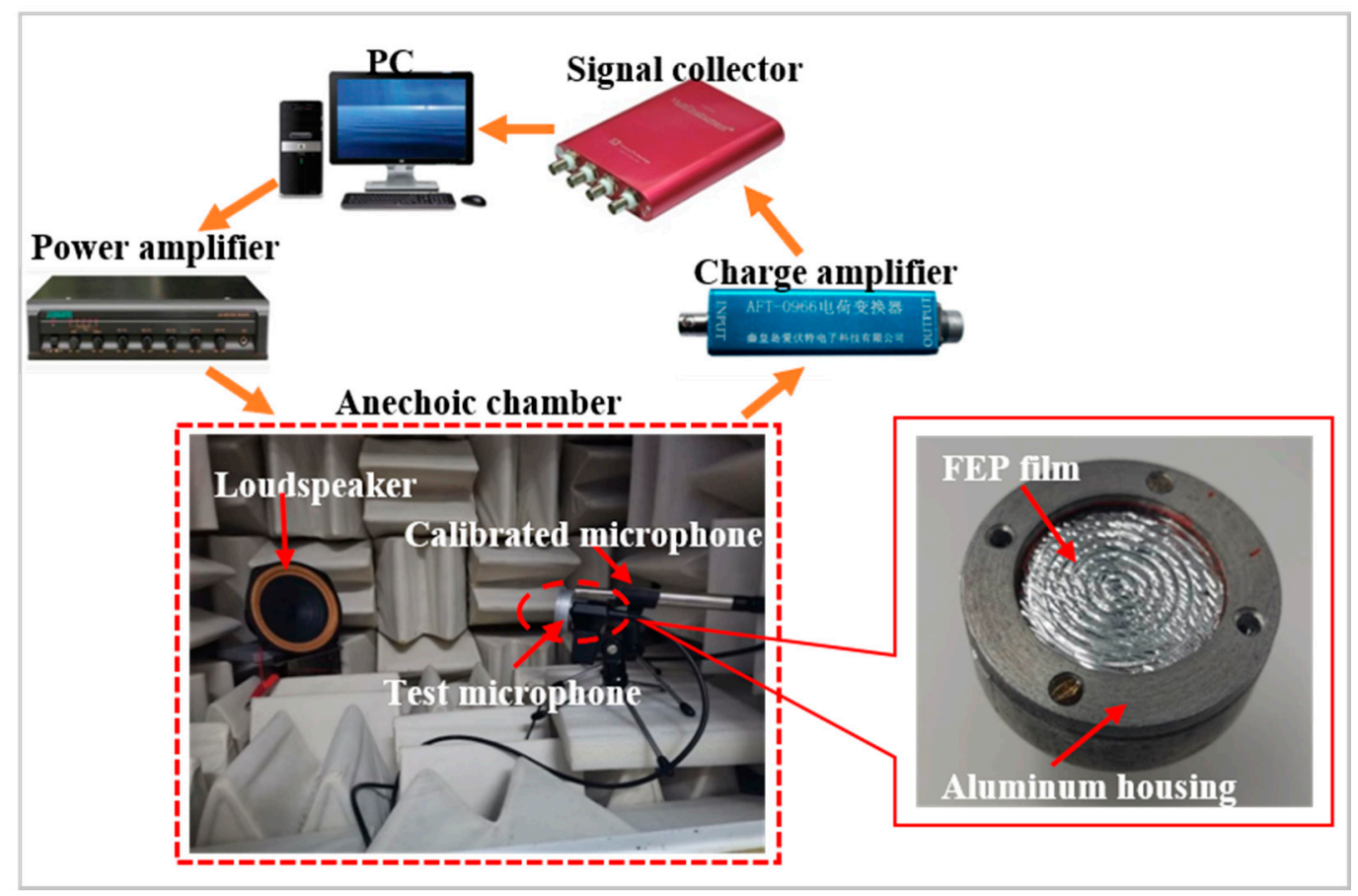

Figure 7. Setup for measurement of the dynamic coefficient $d_{33}$ of the concentric tunnel FEP films by the acoustic method.

Therefore, the pressure sensitivity, $M_{p}$, of the test microphone was obtained from the calibrated microphone using a replacement method as follows [35,36]:

$$
M_{p}=V / p
$$

where $V$ is the output voltage generated by the microphone, and the dynamic coefficient $d_{33}$ was obtained by means of

$$
d_{33}=M_{p} \cdot C / A
$$

where $C$ is the capacitance and $A$ is the area of the sample.

\subsubsection{Acoustic Response}

Results of the dynamic coefficients $d_{33}$ calculated by the acoustic method following Equations (3) and (4) are presented in Figure 8. For the typical samples, dynamic coefficients $d_{33}$ obtained acoustically were 
between 300 and $500 \mathrm{pC} / \mathrm{N}$ at $350 \mathrm{~Hz}$. The acoustic values were much smaller than that determined by the dynamic method, which was calculated as $800 \mathrm{pC} / \mathrm{N}$ at $350 \mathrm{~Hz}$. This must be due to the fact that only very sensitive protruding tunnel parts were excited in the dynamic measurement using a shaker, while the whole sample, including piezoelectrically active tunnel parts and inactive fusion bonding parts, was exposed to the acoustic pressure. Therefore, the averaging piezoelectric coefficients $d_{33}$ obtained acoustically under uniform acoustic waves are smaller than that obtained by the dynamic method [28]. In addition, there exist two response peaks at frequencies of $415 \mathrm{~Hz}$ and $860 \mathrm{~Hz}$, respectively. The resonance peak at $415 \mathrm{~Hz}$ may be related to the bending extension in the radial direction under the sound pressure, and the peak at $860 \mathrm{~Hz}$ is associated with the well-known diffraction of the acoustic wave in acoustic measurements, which happens when the size of the test microphone is comparable or larger than the square of the wavelength [32].

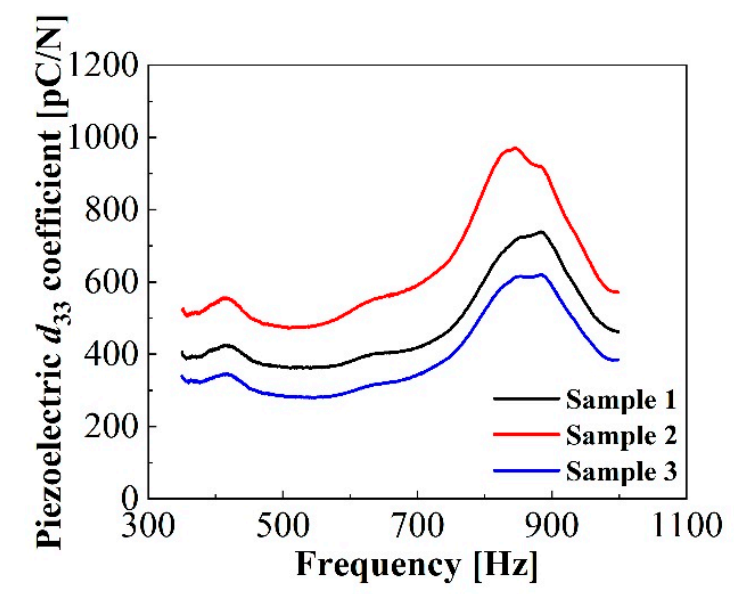

Figure 8. Acoustic dependences of the concentric tunnel FEP films with diameters of $30 \mathrm{~mm}$.

\subsection{Dielectric Resonance Spectrum}

The dielectric resonance spectrum (DRS) was utilized to obtain the electromechanical properties of the concentric tunnel FEP films. Under the two-sided free boundary condition, the measurement was carried out by a precision impedance analyzer (Agilent 4294A). Due to their remarkable radial and longitudinal piezoelectric activities, the radial extension and the thickness extension of samples were visible, which were marked by RE mode and TE mode [37,38]. The RE mode referred to the bending extension in the radial direction, while the TE mode referred to the deformation in the thickness direction when the sample was pressed.

Young's Modulus for the specimen in the thickness direction $\left(Y_{t}\right)$ can be determined by

$$
Y_{t}=4 f_{a}^{2} t \rho_{s}
$$

where $f_{a}$ is the anti-resonance of TE mode, $t$ the thickness of the film, and $\rho_{s}$ the area density. And Young's Modulus in the radial direction $\left(Y_{r}\right)$ is given by

$$
Y_{r}=\left(\frac{2 \pi r f_{a}}{2.08}\right)^{2}\left(1-v^{2}\right) \frac{\rho_{s}}{t}
$$

where $v$ is Poisson's ratio. For foam and polymer, the Poisson's ratio is generally between -0.7 to 0.5 [39]. Unlike the re-entrant structure materials exhibiting a negative Poisson's ratio [40], the value of the concentric tunnel FEP ferroelectrets ranges from 0 to 0.5. As mentioned above, the thickness of the sample is not uniform; therefore, the lower and upper limits of Young's Modulus were calculated from $t_{\max }$ and $t_{\min }$ to obtain $Y_{\max }$ and $Y_{\min }$, respectively [41]. The actual values of $Y_{t}$ and $Y_{r}$ for the concentric tunnel FEP samples must be in between the corresponding values. 
The measuring setup of DRS for the concentric tunnel FEP film sample is shown in Figure 9A. Results of complex capacitance as a function of frequency ranging from 0.1 to $100 \mathrm{kHz}$ for an FEP film sample clearly point out RE and TE modes and corresponding loss peaks at $210 \mathrm{~Hz}$ and $55.6 \mathrm{kHz}$, respectively (see Figure 9B). For all tested samples, the TE mode has a resonance in a frequency range of 50 to $60 \mathrm{kHz}$, which is in agreement with the measurement result of the parallel tunnel samples in [22]. According to Equation (5), taking the maximum and minimum thickness- $t_{\max }=340 \mu \mathrm{m}$ and $t_{\min }=25 \mu \mathrm{m}$ - of the samples quoted above, and the area density of $0.16 \mathrm{~kg} / \mathrm{m}^{2}$, the maximum and minimum limits of the Young's Modulus in the thickness direction for the specimen were determined as $Y_{t \text {-max }}=0.44 \mathrm{MPa}$ and $Y_{t \text {-min }}=0.04 \mathrm{MPa}$, respectively, while the resonance frequencies of RE mode were measured as approximately 200 to $500 \mathrm{~Hz}$, which are lower than those of parallel tunnel samples (at $1.8-6.5 \mathrm{kHz}$ ) [22]. Together with the Poisson's ratio ranging from 0 to 0.5 , the results were used to calculate the Young's Modulus in the radial direction with Equation (6), giving the calculated values of $Y_{r \text {-max }}=45 \mathrm{MPa}$ and $Y_{r \text {-min }}=0.46 \mathrm{MPa}$. The actual values of $Y_{t}$ and $Y_{r}$ for the concentric tunnel FEP films must be in between.

A

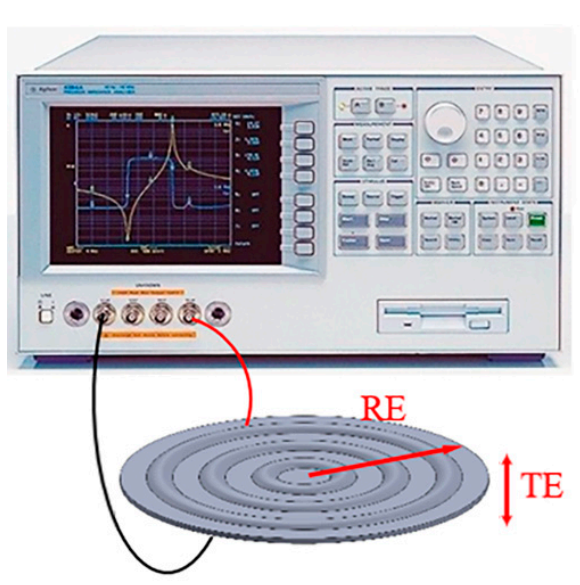

B

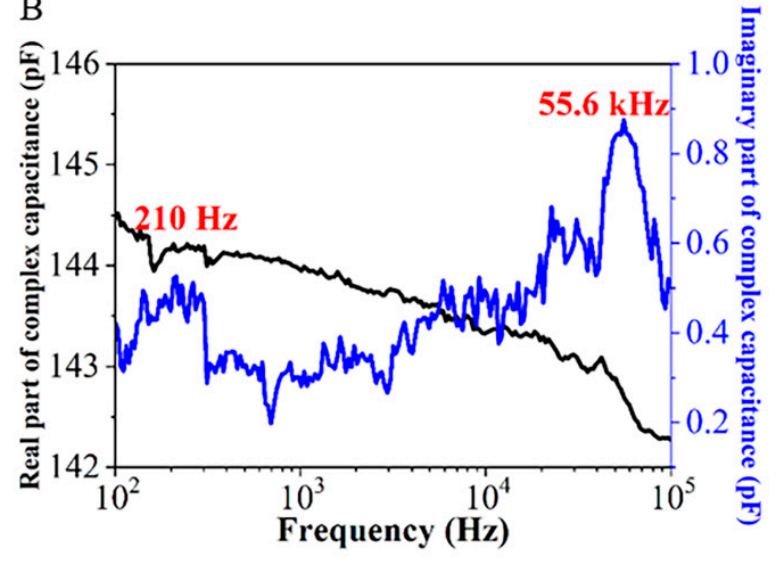

Figure 9. Dielectric responses of a concentric tunnel FEP sample with a diameter of $30 \mathrm{~mm}$. (A) Measurement setup. (B) Dielectric resonance spectrum (DRS) of a concentric tunnel FEP sample.

On the other hand, within the measurement frequency range, the real part of the capacitance is about $140 \mathrm{pF}$ and the imaginary part is less than $1 \mathrm{pF}$. The real part is more than three orders of magnitude higher than the imaginary part. Therefore, the loss of circular tunnel FEP films is considered relatively small, owing to the extremely small conductivity in the FEP ferroelectrets.

\subsection{Measurements of Thermal Stability}

To evaluate the performance of the concentric tunnel FEP films at elevated temperatures, the isothermal decay of $d_{33}$ coefficients at various temperatures and short-circuit thermally stimulated discharge (TSD) current spectra were measured. Firstly, the measurement of the isothermal decay of $d_{33}$ coefficients was conducted. The tested samples were prepared under the same conditions and polarized at room temperature, but stored at room temperature (RT), $90{ }^{\circ} \mathrm{C}$, or $120^{\circ} \mathrm{C}$ for more than $20 \mathrm{~h}$. The curves of the normalized $d_{33}$ coefficient were obtained using a quasi-static method.

Figure 10A shows the isothermal decay curves of the $d_{33}$ coefficients of the concentric tunnel FEP films. The initial $d_{33}$ coefficients of the samples at room temperature (RT), $90{ }^{\circ} \mathrm{C}$, and $120{ }^{\circ} \mathrm{C}$ were 3139 , 2735 , and $3273 \mathrm{pC} / \mathrm{N}$, respectively. The samples stored at $90{ }^{\circ} \mathrm{C}$ and $120^{\circ} \mathrm{C}$ decreased significantly in the first two hours and were basically stable after $6.5 \mathrm{~h}$. After $20 \mathrm{~h}$ annealing, $d_{33}$ coefficients dropped to 3076,1367 , and $982 \mathrm{pC} / \mathrm{N}$, corresponding to about 98,50 , and 35\% of the initial values, respectively. Compared with the thermal stability of PP ferroelectret films [28], which retain only $20 \%$ of the initial value after annealing at $90{ }^{\circ} \mathrm{C}$ for $20 \mathrm{~h}$, concentric tunnel FEP ferroelectret films exhibit higher thermal 
stability, thus ensuring their higher operating temperature. This is because the stability of space charges in FEP is much better than in PP. Besides, the experimental results are in agreement with those of the parallel tunnel FEP films, which prove that the laminated two-layer FEP films with an air-filled tunnel structure have potential applicability at elevated working temperatures [41].
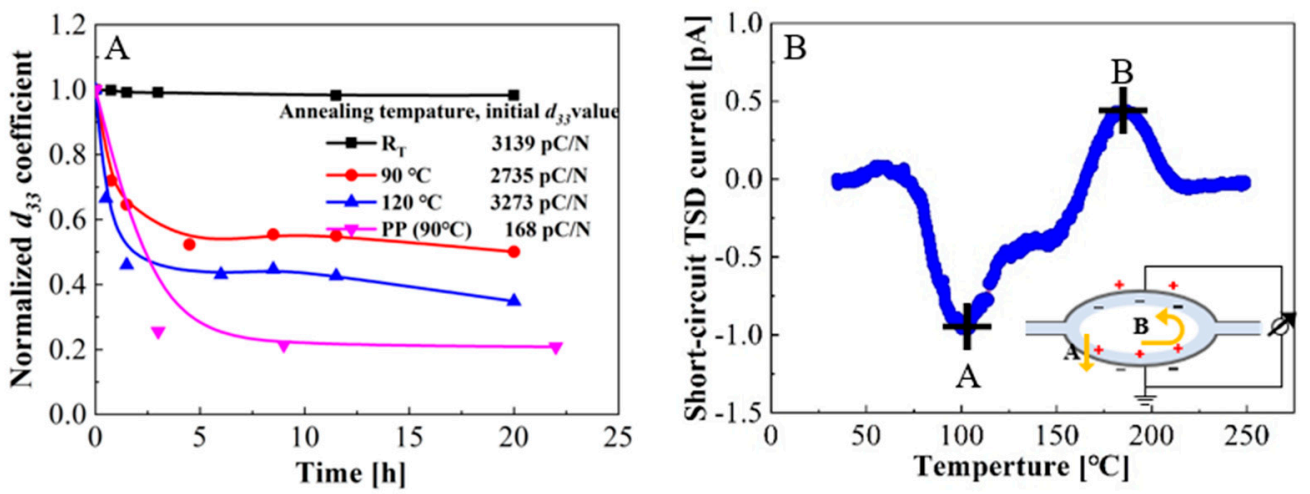

Figure 10. Thermal stability of the concentric tunnel FEP films. (A) Normalized $d_{33}$ coefficients' isothermal decay. (B) Short-circuit thermally stimulated discharge (TSD) current spectrum.

For further study of the thermal stability of charges and distribution of charge traps in the concentric tunnel FEP films, the TSD current spectra were conducted in a short-circuit arrangement [28,42]. The polarized samples were heated in a temperature-controlled chamber where the temperature rose from 30 to $250{ }^{\circ} \mathrm{C}$ at a rate of $3{ }^{\circ} \mathrm{C} / \mathrm{min}$, and the generated current was recorded with an electrometer (Keithley 6514) simultaneously. It is physically impossible to distinguish the contribution of two polar carrier signs. Hence, the short-circuit TSD currents provided information on the overall charge transport processes during discharge.

As shown in Figure 10B, the short-circuit TSD current spectrum comprises a negative peak at $100{ }^{\circ} \mathrm{C}$ and a positive peak at $185^{\circ} \mathrm{C}$. The negative current peak indicates that the positive charges mainly drift through the solid dielectric layer via path $\mathrm{A}$ shown in the inset. When the temperature reached $185^{\circ} \mathrm{C}$, the positive current reached the maximum, revealing that detrapped positive charges favorably moved along the inner surface through path B and were compensated with negative charges. These results are in agreement with those published previously [41].

\section{Fabrication and Performance Assessment of Energy Harvesters}

\subsection{Fabrication of Energy Harvesters}

Combined with the measurement results of the piezoelectric responses introduced above, two energy harvesters, working in 33- or 31-mode, were designed and fabricated to maximize the utilization of their prominent longitudinal and radial piezoelectric responses. Then, the feasibility of concentric tunnel FEP ferroelectrets serving as the transduction material in energy harvesters was evaluated.

The design and the schematic of the working principle of the 33-mode energy harvester are indicated in Figure 11. The 33-mode energy harvester consisted of a top plate, a bottom plate, and an FEP film. For the sake of restricting the deformation of the film in all directions except vertically, the film was fixed on the bottom plate. Hence, the film remained flat during vibration to avoid the effect of bending deformation. The top plate with the same diameter as the film was used as the pre-load. When an external force was applied on the device, the top plate helped distribute the force evenly to each tunnel, thus deforming the tunnels. During vibration, sinusoidal variations of the air-gap thickness led to the change of induced charge density and thus current, $I$, in the external circuit.

The 31-mode energy harvester was designed as having the boundary region fixed and the center part free (see Figure 12). The clampers were made of acrylic plates with a circular hole in the center 
with the same diameter as the samples. When the seismic mass was placed in the center, the tunnels were stretched radially in response to the applied force during vibration, resulting in changes of the dipole moments.

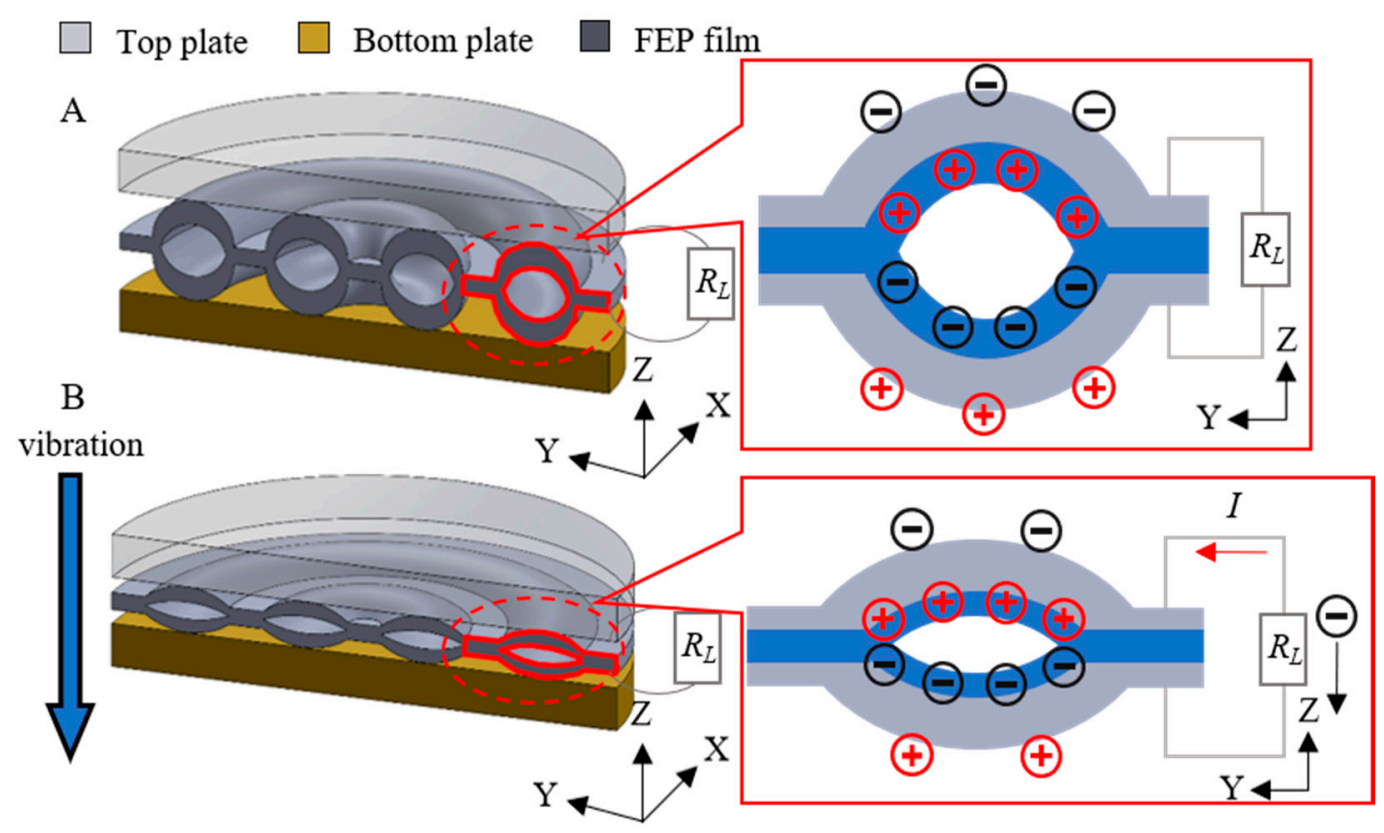

Figure 11. Schematic model and working mechanism of the 33-mode energy harvester. (A) The initial state of the 33-mode energy harvester. (B) The pressed state of the 33-mode energy harvester.

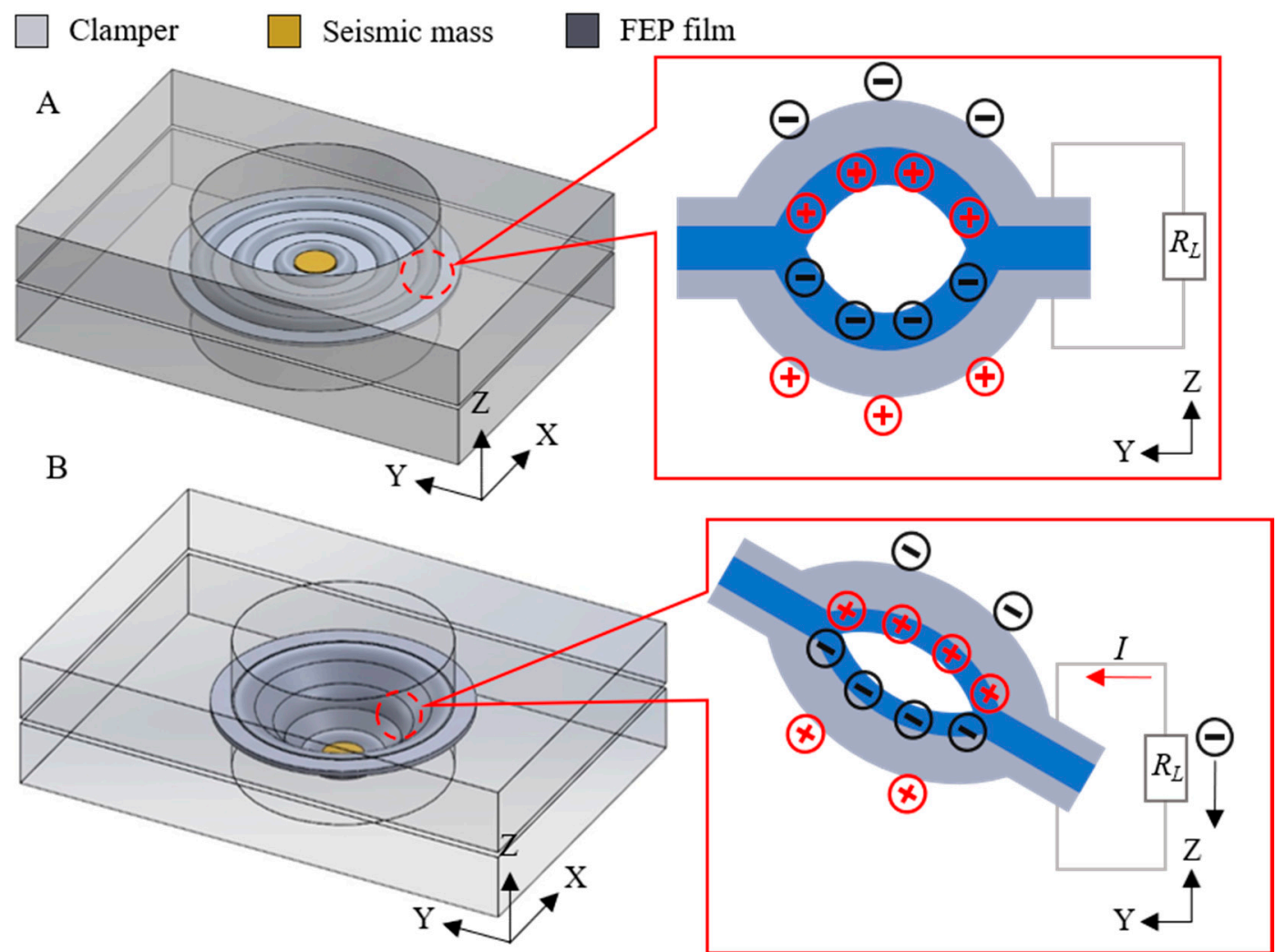

Figure 12. Schematic model and working mechanism of the 31-mode energy harvester. (A) The initial state of the 31-mode energy harvester. (B) The deflected state of the 31-mode energy harvester. 


\subsection{Performance Assessment of Energy Harvesters}

Finally, the performance of two types of energy harvesters was evaluated by the vibration system described above for the dynamic piezoelectric coefficient measurements. The results illustrated the potential of the concentric tunnel FEP films for different working circumstances. Output power was obtained for comparison with other ferroelectret harvesters, which can be calculated by

$$
P_{\text {out }}=\frac{U_{r m s}^{2}}{R_{l}}=R_{l} I_{r m s}^{2}=R_{l} \omega^{2} Q_{r m s}^{2}
$$

where $R_{l}, \omega, U_{r m s}, I_{r m s}$, and $Q_{r m s}$ are the load resistance, operating angular frequency of the energy harvesting system, root mean square (rms) value of voltage, current, and rms charge, respectively.

At resonance angular frequency, $\omega_{0}$, and match resistance, the output power is maximal and can be determined by

$$
P_{\text {out }}=R_{l} I^{2}=\frac{1}{2} R_{\text {opt }} \omega_{0}^{2} Q_{S C}^{2}
$$

where $Q_{S C}$ is the rms value of charge measured in short-circuit and $R_{o p t}$ is the optimal load resistance at the resonance frequency, which can be expressed by

$$
R_{o p t}=\frac{1}{\omega_{0} C}
$$

where $C$ represents the capacitance of the sample.

The normalized output power as a function of vibration frequency for a 33-mode harvester under different seismic masses at an optimal load resistance is shown in Figure 13. The sample had a diameter of $20 \mathrm{~mm}$ and capacitance of $63.5 \mathrm{pF}$, and the seismic masses were 25.5, 33.4, and $41.6 \mathrm{~g}$ with the same diameter as the sample, respectively. As can be seen, the resonance frequency changed with the seismic mass. Hence, different optimal load resistances were determined using Equation (9). The figure indicates that the maximum power of the 33-mode harvester was about $1039 \mu \mathrm{W}$ with the seismic mass of $33.4 \mathrm{~g}$ and optimal load resistance of $12 \mathrm{M} \Omega$ at the resonance frequency of $200 \mathrm{~Hz}$.

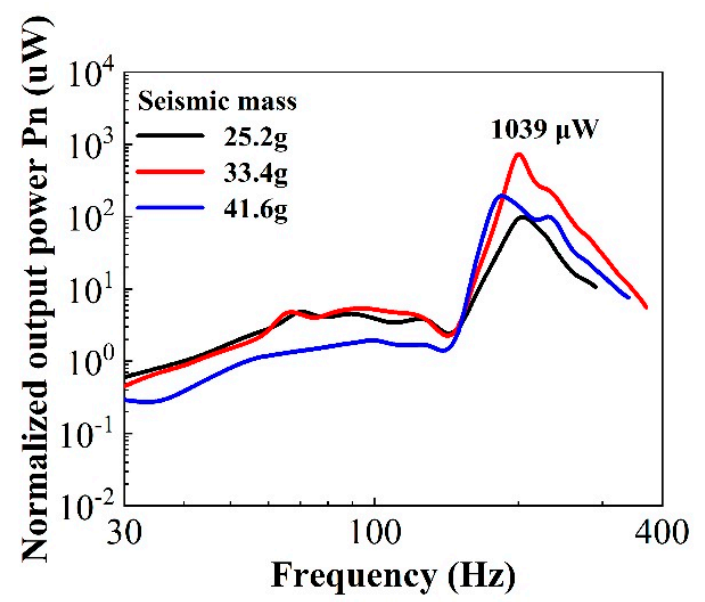

Figure 13. Normalized output power experimental data of the 33-mode energy harvester.

The output performance of the 31-mode harvester was investigated later. Figure 14 gives the experimental data of a representative sample with a diameter of $30 \mathrm{~mm}$. The seismic masses with a diameter of $8 \mathrm{~mm}$ were placed in the centermost part of the sample in order to maximize the radial piezoelectric response. As shown in the figure, the resonance frequencies and normalized output power also changed with increasing seismic mass. With the example of the curve with the seismic mass of $1.9 \mathrm{~g}$, marked in blue, given $C=176.8 \mathrm{pF}$ and $f_{0}=26.3 \mathrm{~Hz}$, the optimal load resistance $R_{\mathrm{opt}}$ 
was calculated as $34 \mathrm{M} \Omega$ and the maximum output power was determined as approximately $15 \mu \mathrm{W}$ following Equation (8).

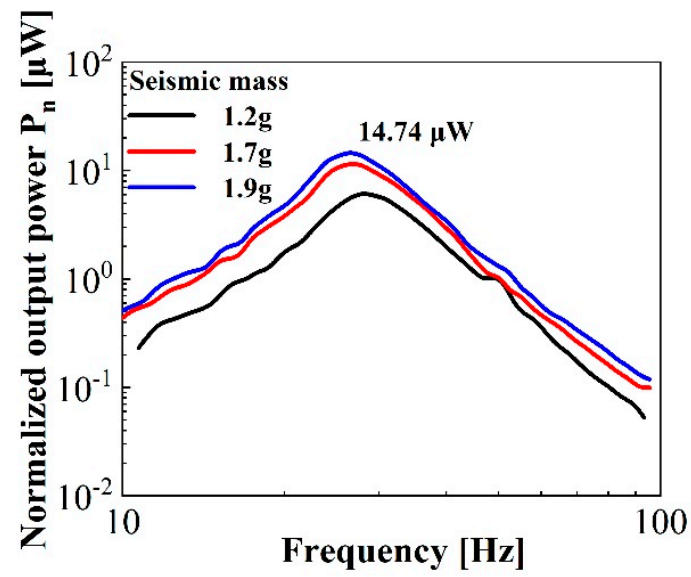

Figure 14. Normalized output power experimental data of the 31-mode energy harvester.

In order to compare the performance of the 33-mode and 31-mode energy harvesters with other small scale harvesters, the area power density was defined as $P_{a}=P_{m} / A$, where $P_{m}$ is the maximum power generated by the harvester at the resonance frequency, optimal resistance, and appropriate seismic mass, and $A$ is the active area of the harvester. Substituting the experimental values of $P_{m}=1039$ and $15 \mu \mathrm{W}$ and $A=3.14$ and $7.07 \mathrm{~cm}^{2}$ for the 33- and 31-mode devices, respectively, the area power densities are $331 \mu \mathrm{W} / \mathrm{cm}^{2}$ and $2.12 \mu \mathrm{W} / \mathrm{cm}^{2}$, respectively. As shown in Table 1, the area power density of the 33-mode harvester exceeds that of other nanogenerators using other materials, such as PVDF, PDMS, and IXPP, and is close to the power density generated by the parallel tunnel structure FEP ferroelectrets. However, it should be kept in mind that the appropriate load mass of $33.4 \mathrm{~g}$ was applied to a sample with an area of $3.14 \mathrm{~cm}^{2}$, corresponding to a pressure of $1 \mathrm{kPa}$, which is larger than the load pressure in other studies. It proves that the FEP ferroelectret films with a tunnel structure are excellent piezoelectric transduction materials for energy harvesting.

Table 1. Recent progress of other small-scale harvesters.

\begin{tabular}{cccc}
\hline Type & $\begin{array}{c}\text { Area Power } \\
\text { Density }\end{array}$ & $\begin{array}{c}\text { Pressure or } \\
\text { Seismic Mass }\end{array}$ & References \\
\hline PVDF/KNN/ZnO electrospun nanofibers & $11.31 \mu \mathrm{W} / \mathrm{cm}^{2}$ & $\sim 1 \mathrm{kPa}$ & {$[43]$} \\
PVDF/BT nanoparticles & $120 \mu \mathrm{W} / \mathrm{cm}^{2}$ & - & {$[44]$} \\
$\mathrm{ZnSnO}_{3}$ nanowires/PDMS & $230 \mu \mathrm{W} / \mathrm{cm}^{2}$ & $>100 \mathrm{~N}$ & {$[45]$} \\
$\mathrm{MASnBr}_{3} /$ PDMS & $74.52 \mu \mathrm{W} / \mathrm{cm}^{2}$ & $\sim 0.5 \mathrm{MPa}$ & {$[46]$} \\
IXPP ferroelectret (33-mode) & $57.32 \mu \mathrm{W} / \mathrm{cm}^{2}$ & $33.7 \mathrm{~g}$ & {$[47]$} \\
FEP ferroelectret (out-of-plane type) & $150 \mu \mathrm{W} / \mathrm{cm}^{2}$ & $10 \mathrm{~g}$ & {$[48]$} \\
Cross-tunnel FEP ferroelectret (33-mode) & $0.12 \mu \mathrm{W} / \mathrm{cm}^{2}$ & $69.5 \mathrm{~g}$ & {$[49]$} \\
Parallel tunnel FEP ferroelectret (33-mode) & $462.5 \mu \mathrm{W} / \mathrm{cm}^{2}$ & $80 \mathrm{~g}$ & {$[50]$} \\
Parallel tunnel FEP ferroelectret (31-mode) & $95.83 \mu \mathrm{W} / \mathrm{cm}^{2}$ & $2 \mathrm{~g}$ & {$[28]$} \\
Parallel tunnel FEP ferroelectret (31-mode) advanced design & $272.5 \mu \mathrm{W} / \mathrm{cm}^{2}$ & $0.3 \mathrm{~g}$ & {$[22]$} \\
Cantilever-based parallel tunnel FEP ferroelectret (31-mode) & $106.7 \mu \mathrm{W} / \mathrm{cm}^{2}$ & $4.5 \mathrm{~g}$ & {$[29]$} \\
Concentric tunnel FEP ferroelectret (33-mode) & $331 \mu \mathrm{W} / \mathrm{cm}^{2}$ & $33.4 \mathrm{~g}$ & This work \\
Concentric tunnel FEP ferroelectret (31-mode) & $2.12 \mu \mathrm{W} / \mathrm{cm}^{2}$ & $2.0 \mathrm{~g}$ & This work \\
\hline
\end{tabular}

For the 31-mode harvester, however, the area power density was two orders of magnitude lower than the parallel tunnel structure FEP films. The reason for this is that when PCDs are subjected to annular clamping, the boundary region has a very small effective strain and the amplitude of the center part is also small. At the same time, it is difficult for air in the enclosed concentric tunnels to be released during vibration, especially at low frequencies, which will affect the deformation of the tunnels. It is 
expected that by designing new shapes of concentric tunnel structures, such as a complete disc cut into propeller shapes, the output power can be significantly increased. Relevant work is underway.

\section{Summary and Discussion}

In conclusion, FEP bipolar ferroelectret films with a specifically designed concentric tunnel structure were prepared by means of rigid template-based thermoplastic molding and contact polarization. The fabricated films featured both remarkable longitudinal and radial piezoelectric activities, as well as superior thermal stability. For the longitudinal piezoelectric activity, a quasi-static piezoelectric $d_{33}$ coefficient of up to $5280 \mathrm{pC} / \mathrm{N}$ was achieved. For the radial piezoelectric activity, the piezoelectric sensitivity, $M_{\mathrm{r}}$, of $40,000 \mathrm{pC} / \mathrm{N}$ was obtained in a sample with a diameter of $30 \mathrm{~mm}$ at a static force of $200 \mathrm{mN}$.

For energy harvesting with such concentric tunnel FEP ferroelectret films, power output of up to $1 \mathrm{~mW}$ was achieved in an energy harvester working in 33-mode and at $210 \mathrm{~Hz}$, referring to a seismic mass of $33.4 \mathrm{~g}$ and an acceleration of $1 \mathrm{~g}$. For a device working in 31-mode, the power output of $15 \mu \mathrm{W}$ was obtained at a relatively small resonance frequency of $26 \mathrm{~Hz}$ and a very light seismic mass of $1.9 \mathrm{~g}$. Besides, our experimental results on the fatigue resistance (not shown here) show that the stable output power of the devices was around $90 \%$ after more than 1 million operation cycles. Therefore, depending on specific circumstances, such films provide flexible options for designing vibrational energy harvesters working either in 33-mode or 31-mode.

Author Contributions: X.Z. (Xi Zuo): conceptualization, writing—original draft preparation, writing-review and editing, methodology, validation, data curation; L.C.: conceptualization, methodology, validation, investigation, data curation; W.P.: writing - original draft preparation, methodology, validation, investigation, data curation; X.M.: conceptualization, writing - original draft preparation, methodology, validation, data curation; T.Y.: writing-original draft preparation, resources, project administration, funding acquisition; X.Z. (Xiaoqing Zhang): conceptualization, writing-original draft preparation, writing-review and editing, methodology, resources, data curation, project administration, funding acquisition. All authors have read and agreed to the published version of the manuscript.

Funding: This research was funded by the National Natural Science Foundation of China (NSFC, 61761136004).

Acknowledgments: Financial support from the Natural Science Foundation of China (NSFC, 61761136004) is gratefully acknowledged.

Conflicts of Interest: The authors declare no conflict of interest.

\section{References}

1. Shi, Q.; Dong, B.; He, T.; Sun, Z.; Zhu, J.; Zhang, Z.; Lee, C. Progress in wearable electronics/photonics-Moving toward the era of artificial intelligence and internet of things. Infomat 2020, 2, 1131-1162. [CrossRef]

2. Chen, G.; Li, Y.; Bick, M.; Chen, J. Smart Textiles for Electricity Generation. Chem. Rev. 2020, 120, 3668-3720. [CrossRef] [PubMed]

3. Zhu, J.; Liu, X.; Shi, Q.; He, T.; Sun, Z.; Guo, X.; Liu, W.; Sulaiman, O.B.; Dong, B.; Lee, C. Development Trends and Perspectives of Future Sensors and MEMS/NEMS. Micromachines 2020, 11, 7. [CrossRef] [PubMed]

4. Jackson, N. PiezoMEMS Nonlinear Low Acceleration Energy Harvester with an Embedded Permanent Magnet. Micromachines 2020, 11, 500. [CrossRef] [PubMed]

5. Roundy, S.; Wright, P.K.; Rabaey, J. A study of low level vibrations as a power source for wireless sensor nodes. Comput. Commun. 2003, 26, 1131-1144. [CrossRef]

6. Erturk, A.; Inman, D.J. Introduction to Piezoelectric Energy Harvesting; John Wiley \& Sons, Ltd.: Hoboken, NJ, USA, 2011.

7. Covaci, C.; Gontean, A. Piezoelectric Energy Harvesting Solutions: A Review. Sensors 2020, $20,3512$. [CrossRef] [PubMed]

8. Dong, K.; Peng, X.; Wang, Z. Fiber/Fabric-Based Piezoelectric and Triboelectric Nanogenerators for Flexible/Stretchable and Wearable Electronics and Artificial Intelligence. Adv. Mater. 2020, 32, 1902549. [CrossRef] 
9. Jiao, P.; Egbe, K.J.I.; Xie, Y.; Nazar, A.M.; Alavi, A.H. Piezoelectric Sensing Techniques in Structural Health Monitoring: A State-of-the-Art Review. Sensors 2020, 20, 3730. [CrossRef]

10. Fan, K.; Zhang, Y.; E, S.; Tang, L.; Qu, H. A string-driven rotor for efficient energy harvesting from ultra-low frequency excitations. Appl. Phys. Lett. 2019, 115, 203903. [CrossRef]

11. Elahi, H.; Eugeni, M.; Fune, F.; Lampani, L.; Mastroddi, F.; Paolo Romano, G.; Gaudenzi, P. Performance Evaluation of a Piezoelectric Energy Harvester Based on Flag-Flutter. Micromachines 2020, 11, 933. [CrossRef]

12. Yang, Y.; Wang, S.; Stein, P.; Xu, B.; Yang, T. Vibration-based energy harvesting with a clamped piezoelectric circular diaphragm: Analysis and identification of optimal structural parameters. Smart Mater. Struct. 2017, 26, 045011. [CrossRef]

13. Lei, Z.; Chen, Y.; Xu, G.; Liu, J.; Yuan, M.; Zeng, L.; Ji, X.; Wu, D. Micromachining of High Quality PMN-31\%PT Single Crystals for High-Frequency (>20 MHz) Ultrasonic Array Transducer Applications. Micromachines 2020, 11, 512. [CrossRef] [PubMed]

14. Fei, C.; Zhao, T.; Wang, D.; Quan, Y.; Lin, P.; Li, D.; Yang, Y.; Cheng, J.; Wang, C.; Wang, C.; et al. High Frequency Needle Ultrasonic Transducers Based on Lead-Free Co Doped $\mathrm{Na}_{0.5} \mathrm{Bi}_{4.5} \mathrm{Ti}_{4} \mathrm{O}_{15}$ Piezo-Ceramics. Micromachines 2018, 9, 291. [CrossRef] [PubMed]

15. Shin, Y.; Jung, I.; Park, H.; Pyeon, J.; Son, J.; Koo, C.; Kim, S.; Kang, C. Mechanical Fatigue Resistance of Piezoelectric PVDF Polymers. Micromachines 2018, 9, 503. [CrossRef]

16. Baginsky, I.; Kostsov, E.; Sokolov, A. Single-Capacitor Electret Impact Microgenerator. Micromachines 2016, 7, 5. [CrossRef]

17. Ma, X.; Zhang, X.; Fang, P. Flexible film-transducers based on polypropylene piezoelectrets: Fabrication, properties, and applications in wearable devices. Sens. Actuators A Phys. 2017, 256, 35-42. [CrossRef]

18. Ma, X.; Zhang, X.; Sessler, G.M.; Chen, L.; Yang, X.; Dai, Y.; He, P. Energy harvesters based on fluorinated ethylene propylene unipolar ferroelectrets with negative charges. AIP Adv. 2019, 9, 125334. [CrossRef]

19. Gerhard-Multhaupt, R. Less can be more-Holes in polymers lead to a new paradigm of piezoelectric materials for electret transducers. IEEE Trans. Dielectr. Electr. Insul. 2002, 9, 850-859. [CrossRef]

20. Zhang, X.; Huang, J.; Chen, J.; Wan, Z.; Wang, S.; Xia, Z. Piezoelectric properties of irradiation-crosslinked polypropylene ferroelectrets. Appl. Phys. Lett. 2007, 91, 182901. [CrossRef]

21. Chen, L.; Cao, J.; Li, G.; Fang, P.; Gong, X.; Zhang, X. Property Assessment and Application Exploration for Layered Polytetrafluoroethylene Piezoelectrets. IEEE Sens. J. 2019, 19, 11262-11271. [CrossRef]

22. Zhang, X.; Pondrom, P.; Sessler, G.M.; Ma, X. Ferroelectret nanogenerator with large transverse piezoelectric activity. Nano Energy 2018, 50, 52-61. [CrossRef]

23. Ko, W.; Chen, J.; Wu, W.; Lee, C. A double-sided electret polymer film-based electrostatic actuator. Electroact. Polym. Actuators Devices 2008, 6927, 69271V. [CrossRef]

24. Fang, P.; Wirges, W.; Wegener, M.; Zirkel, L.; Gerhard, R. Cellular polyethylene-naphthalate films for ferroelectret applications: Foaming, inflation and stretching, assessment of electromechanically relevant structural features. E-Polymers 2008, 8. [CrossRef]

25. Kim, S.; Suzuki, K.; Sugie, A.; Yoshida, H.; Yoshida, M.; Suzuki, Y. Effect of end group of amorphous perfluoro-polymer electrets on electron trapping. Sci. Technol. Adv. Mater. 2018, 19, 486-494. [CrossRef]

26. Zhukov, S.; Ma, X.; von Seggern, H.; Sessler, G.M.; Ben Dali, O.; Kupnik, M.; Zhang, X. Biodegradable cellular polylactic acid ferroelectrets with strong longitudinal and transverse piezoelectricity. Appl. Phys. Lett. 2020, 117, 112901. [CrossRef]

27. Zhang, X.; Hillenbrand, J.; Sessler, G.M. Ferroelectrets with improved thermal stability made from fused fluorocarbon layers. J. Appl. Phys. 2007, 101, 054114. [CrossRef]

28. Zhang, X.; Pondrom, P.; Wu, L.; Sessler, G.M. Vibration-based energy harvesting with piezoelectrets having high d(31) activity. Appl. Phys. Lett. 2016, 108, 193903. [CrossRef]

29. Ben Dali, O.; Pondrom, P.; Sessler, G.M.; Zhukov, S.; von Seggern, H.; Zhang, X.; Kupnik, M. Cantilever-based ferroelectret energy harvesting. Appl. Phys. Lett. 2020, 116, 243901. [CrossRef]

30. von Seggern, H.; Zhukov, S.; Fedosov, S.N. Poling Dynamics and Thermal Stability of FEP/ePTFE/FEP Sandwiches. IEEE Trans. Dielectr. Electr. Insul. 2010, 17, 1056-1065. [CrossRef]

31. Zhang, X.; Hillenbrand, J.; Sessler, G.M.; Haberzettl, S.; Lou, K. Fluoroethylenepropylene ferroelectrets with patterned microstructure and high, thermally stable piezoelectricity. Appl. Phys. A. 2012, 107, 621-629. [CrossRef] 
32. Zhukov, S.; Eder-Goy, D.; Fedosov, S.; Xu, B.; von Seggern, H. Analytical prediction of the piezoelectric d(33) response of fluoropolymer arrays with tubular air channels. Sci. Rep. UK 2018, 8, 4597. [CrossRef] [PubMed]

33. Wang, Y.; Wu, L.; Zhang, X. Energy Harvesting from Vibration Using Flexible Floroethylenepropylene Piezoelectret Films with Cross-tunnel Structure. IEEE Trans. Dielectr. Electr. Insul. 2015, 22, 1349-1354. [CrossRef]

34. Xue, Y.; Zhao, J.; Zhang, X.; Sessler, G.M.; Kupnik, M. Acoustic energy harvesting with irradiated cross-linked polypropylene piezoelectret films. Phys. Scripta 2019, 94. [CrossRef]

35. Xue, Y.; Zhang, X. Air-coupled Ultrasonic Transducers based on Laminated Fluorinated Ethylene Propylene and Porous Polytetrafluoroethylene Ferroelectrets. IEEE Trans. Dielectr. Electr. Insul. 2018, 25, 808-815. [CrossRef]

36. Mellinger, A. Dielectric resonance spectroscopy: A versatile tool in the quest for better piezoelectric polymers. IEEE Trans. Dielectr. Electr. Insul. 2003, 10, 842-861. [CrossRef]

37. Neugschwandtner, G.S.; Schwodiauer, R.; Vieytes, M.; Bauer-Gogonea, S.; Bauer, S.; Hillenbrand, J.; Kressmann, R.; Sessler, G.M.; Paajanen, M.; Lekkala, J. Large and broadband piezoelectricity in smart polymer-foam space-charge electrets. Appl. Phys. Lett. 2000, 77, 3827-3829. [CrossRef]

38. Gibson, L.J.; Ashby, M.F. Cellular Solids: Structure and Properties, 2nd ed.; Cambridge University Press: Cambridge, UK, 1997.

39. Brandel, B.; Lakes, R.S. Negative Poisson's ratio polyethylene foams. J. Mater. Sci. 2001, 36, 5885-5893. [CrossRef]

40. Ma, X.; von Seggern, H.; Sessler, G.M.; Zhukov, S.; Ben Dali, O.; Kupnik, M.; Zhang, X. High performance fluorinated polyethylene propylene ferroelectrets with an air-filled parallel-tunnel structure. Smart Mater. Struct. 2020. [CrossRef]

41. Bauer, S. Piezo-, pyro- and ferroelectrets: Soft transducer materials for electromechanical energy conversion. IEEE Trans. Dielectr. Electr. Insul. 2006, 13, 953-962. [CrossRef]

42. Bairagi, S.; Ali, S.W. A hybrid piezoelectric nanogenerator comprising of $\mathrm{KNN} / \mathrm{ZnO}$ nanorods incorporated PVDF electrospun nanocomposite webs. Int. J. Energy Res. 2020, 44, 5545-5563. [CrossRef]

43. Gaur, A.; Tiwari, S.; Kumar, C.; Maiti, P. Flexible, Lead-Free Nanogenerators Using Poly(vinylidene fluoride) Nanocomposites. Energy Fuel 2020, 34, 6239-6244. [CrossRef]

44. Rovisco, A.; dos Santos, A.; Cramer, T.; Martins, J.; Branquinho, R.; Aguas, H.; Fraboni, B.; Fortunato, E.; Martins, R.; Igreja, R.; et al. Piezoelectricity Enhancement of Nanogenerators Based on PDMS and $\mathrm{ZnSnO}_{3}$ Nanowires through Microstructuration. ACS Appl. Mater. Interfaces 2020, 12, 18421-18430. [CrossRef] [PubMed]

45. Ippili, S.; Jella, V.; Kim, J.; Hong, S.; Yoon, S.G. Unveiling Predominant Air-Stable Organotin Bromide Perovskite toward Mechanical Energy Harvesting. ACS Appl Mater. Interfaces 2020, 12, 16469-16480. [CrossRef]

46. Zhang, X.; Wu, L.; Sessler, G.M. Energy harvesting from vibration with cross-linked polypropylene piezoelectrets. AIP Adv. 2015, 5, 077185. [CrossRef]

47. Pondrom, P.; Sessler, G.M.; Bos, J.; Melz, T. Compact electret energy harvester with high power output. Appl. Phys. Lett. 2016, 109, 053906. [CrossRef]

48. Zhang, X.; Sessler, G.M.; Wang, Y. Fluoroethylenepropylene ferroelectret films with cross-tunnel structure for piezoelectric transducers and micro energy harvesters. J. Appl. Phys. 2014, 116, 074109. [CrossRef]

49. Zhang, X.; Sessler, G.M.; Ma, X.; Xue, Y.; Wu, L. Broad bandwidth vibration energy harvester based on thermally stable wavy fluorinated ethylene propylene electret films with negative charges. J. Micromech. Microeng. 2018, 28, 065012. [CrossRef]

50. Yang, Y.; Li, Y.; Guo, Y.; Xu, B.; Yang, T. Improved vibration-based energy harvesting by annular mass configuration of piezoelectric circular diaphragms. Smart Mater. Struct. 2018, 27, 035004. [CrossRef]

Publisher's Note: MDPI stays neutral with regard to jurisdictional claims in published maps and institutional affiliations. 